\title{
Neuregulin 3 Signaling Mediates Nicotine-Dependent Synaptic Plasticity in the Orbitofrontal Cortex and Cognition
}

\author{
Luyi Zhou ${ }^{1,2}$, Miranda L Fisher', Robert D Cole ${ }^{3}$, Thomas J Gould ${ }^{4}$, Vinay Parikh ${ }^{3}$, Pavel I Ortinski ${ }^{2,5}$ and \\ Jill R Turner $*, 1,5$ \\ 'Department of Drug Discovery and Biomedical Sciences, College of Pharmacy, University of South Carolina, Columbia, SC, USA; ${ }^{2}$ Department of \\ Pharmacology, Physiology, and Neuroscience, University of South Carolina School of Medicine, Columbia, SC, USA; ${ }^{3}$ Department of Psychology, \\ Temple University, Philadelphia, PA, USA; ${ }^{4}$ Department of Biobehavioral Health, Pennsylvania State University, University Park, PA, USA
}

\begin{abstract}
Neuregulin 3 (NRG3) and ErbB4 have been linked to nicotine addiction; however, the neuronal mechanisms and behavioral consequences of NRG3-ErbB4 sensitivity to nicotine remain elusive. Recent literature suggests that relapse to smoking is due to a lack of impulsive control, which is thought to be due to altered functioning within the orbitofrontal cortex (OFC). Therefore, we examined circuitry changes within this structure following nicotine application. We report that nicotine controls synaptic plasticity in the OFC through NRG3/ErbB4dependent regulation of GABAergic inhibition. We observed that both nicotine and NRG3 facilitated the conversion of long-term potentiation into long-term depression at cortical layer 3/5 synapses. Induction of long-term depression by nicotine relied on nicotinic receptor activation and key regulators of NRG3 signaling: (I) release of intracellular calcium, (2) activation of the BACEI beta-secretase, and (3) ErbB4 receptor activation. Nicotine-induced synaptic plasticity was also associated with accumulation of intracellular GABA and was completely blocked by $\mathrm{GABA}_{A} / \mathrm{GABA}_{B}$ antagonists. To test whether these mechanisms underlie OFC-dependent behavior, we evaluated the effects of nicotine in the go/no-go task. Nicotine-impaired stimulus discrimination in this task was rescued by pharmacologic disruption of the NRG3 receptor, ErbB4. Altogether, our data indicate that nicotine-induced synaptic plasticity in the OFC and cognitive changes depend on NRG3-ErbB4 signaling. We propose that nicotine activation of this pathway may contribute to nicotine addiction, particularly in individuals with genetic variation in NRG3.
\end{abstract}

Neuropsychopharmacology (20 I8) 43, 1343-1354; doi: I 0. I038/npp.2017.278; published online 20 December 2017

\section{INTRODUCTION}

Tobacco smoking is the leading cause of preventable death in the world, responsible for $\sim 6$ million deaths each year (2016). Despite the health risks, $\sim 18 \%$ of the general U.S. population smokes (Jamal et al, 2014). Several pharmacotherapies are currently available for nicotine dependence; however, relapse is common and smoking cessation is successful in $<5 \%$ of quit attempts (Nides, 2008). These high rates of relapse to smoking may be due to genetic factors. Heritability of nicotine dependence is estimated at $40-75 \%$ (Rose et al, 2009) and genome-wide association studies have identified a number of associated risk alleles. Genes encoding a member of the epidermal growth factor family, neuregulin 3 (NRG3), and its receptor, ErbB4, have been recently linked to smoking cessation outcomes (Loukola et al, 2014; Turner et al, 2014). These genes are of particular interest due to their therapeutic potential, with downstream targets under

\footnotetext{
*Correspondence: Dr JR Turner, Department of Drug Discovery and Biomedical Sciences, University of South Carolina, 7I 5 Sumter St, Coker Life Sciences Bldg, Rm 513, Columbia, SC 29208, USA, Tel: +(803) 777-70 I I, E-mail: JITurner@sccp.sc.edu

${ }^{5}$ These authors contributed equally to this work

Received I6 May 2017; revised 2 October 20 I7; accepted 24 October 2017; accepted article preview online 7 November 2017
}

therapeutic development for several neuropsychiatric disorders. For example, NRG3-ErbB4 signaling is shown to regulate activity of the protein PI3K (Krivosheya et al, 2008), which is being examined as a potential target for treatment of schizophrenia (Papaleo et al, 2016).

Smoking has been consistently shown to reduce the thickness of gray matter volume in the OFC, a brain region involved in decision making and processing of rewardrelated information (Kuhn et al, 2010; Li et al, 2015; Tremblay and Schultz, 2000; Volkow and Fowler, 2000). Acute nicotine increases blood oxygen level dependent (BOLD) fMRI signal in the striato-thalamo-orbitofrontal circuit (Bruijnzeel et al, 2015) and the behavioral effects of nicotine exposure on this circuit have been extensively studied (Ashare et al, 2014). Neuronal mechanisms underlying such effects, however, are not readily ascertained since nicotine facilitates release of multiple neurotransmitters, including glutamate, GABA, and dopamine, which may result in facilitation as well as suppression of neuronal output (Alkondon et al, 2000; Ji and Dani, 2000; Ji et al, 2001; Turner, 2004; Wang et al, 2006). Nicotine has been reported to enhance long-term potentiation (LTP) in a number of brain regions, including hippocampus (Nakauchi and Sumikawa, 2012), amygdala (Huang et al, 2008), and ventral tegmental area (Mansvelder and McGehee, 2000). Few 
studies have evaluated the effects of nicotine on plasticity in frontocortical areas, although one report showed that nicotine raised the threshold for LTP induction in the prefrontal cortex by enhancing GABAergic transmission (Couey et al, 2007). Although GABAergic interneurons throughout the brain are enriched with ErbB4 receptors (Bean et al, 2014; Loos et al, 2014), ErbB4 receptor interaction with nicotinic signals has yet to be examined in the context of synaptic plasticity in the OFC.

We, and others, have previously shown that transcriptional regulation of NRG3-ErbB4 signaling regulates behavioral symptoms of anxiety induced by nicotine withdrawal (Bi et al, 2015; Turner et al, 2014). This is consistent with epidemiological studies suggesting that nicotine dependence increases the risk of anxiety disorders and panic attacks (Bruijnzeel, 2012), although tobacco smoking has also been reported to exert anxiolytic effects that may underlie the addiction potential of nicotine (Gilbert et al, 1989; Torres and O'Dell, 2016). Frontocortical activation, including the OFC, has been implicated in processing anxiety and anxietydependent cognitive traits of attention and impulsivity, all of which are strongly dysregulated in nicotine dependence (Gold et al, 2015; Rauch et al, 2007; Ursu and Carter, 2009). To evaluate these behaviors in rodents, we used a go/no-go discrimination task that allows for discrimination between measures of attention and impulsivity in mice, as a behavioral read-out of the link between nicotine and NRG3 signaling. To mechanistically understand how nicotine and NRG3 interact to influence OFC functionality, we utilized electrophysiological and molecular approaches with the overall goal of identifying a putative pathway by which nicotine triggers NRG3/ErbB4 signaling resulting in nicotine-induced behaviors. Understanding of the mechanics of this pathway and its connection with nicotine has clinical potential, particularly in individuals with genetic risk variations in NRG3 that have been found associated with smoking cessation outcomes.

\section{MATERIALS AND METHODS}

\section{Animals and Housing}

Male B6/129F1 and NRG3 ${ }^{\text {ska }}$ (Jackson Laboratories; 610 weeks of age; $20-25 \mathrm{~g}$ ) were used in both the electrophysiology and molecular experiments. NRG3 ${ }^{\text {ska }}$ mice arose as a spontaneous mutation, which was later identified as a microsatellite repeat within intron 7 of the Nrg3 gene; strain of origin is $\mathrm{A} / \mathrm{J}$, which also possess this mutation. In previous experiments, the B6/129 F1 mice have been successfully utilized as a control line for these animals by providing widely comparable mice that can be used for testing, show hybrid vigor, and do not display genetic drift (Turner et al, 2014). Both B6/129F1 and NRG3 $3^{\text {ska }}$ subjects were grouphoused in a colony room with ad libitum food and water access and were maintained on a 12-h light/dark cycle, with lights on at 0700 hours in accordance with the University of South Carolina Animal Care and Use Committee. For behavioral studies, C57BL/6J (Jackson Laboratories, 610 weeks; 20-25 g) mice were employed due to their widespread use as controls in previous go/no-go and attentional experiments (Cole et al, 2015; D'Amore et al, 2013; Ortega et al, 2013) and their close relation to the
C57/129 F1 hybrids. The C57BL/6J mice were housed individually with ad libitum food but progressively water restricted to $5 \mathrm{~min}$ of water per day in addition to sweetened water received as a reward for each correct response (see below). All behavioral training and testing took place 7 days/ week between 0900 and 1600 hours in accordance with the Animal Care and Use Committee of Temple University.

\section{Drugs}

The following compounds and drugs were used in this study: (-)-Nicotine hydrogen tartrate (MP Biomedicals, Santa Ana, CA); NRG3 (Sino Biological, Beijing, China); ErbB4 inhibitor, afatinib (LC Laboratories, Woburn, MA); $\mathrm{GABA}_{\mathrm{A}}$ receptor antagonist, picrotoxin (Acros Organics, NJ); $\mathrm{GABA}_{\mathrm{B}}$ receptor antagonist, CGP55845; NMDA antagonist, DL-AP5; $\alpha 7$ nicotinic acetylcholine receptor (nAChR) antagonist, $\alpha$-Bungarotoxin; $\alpha 4 \beta 2 \mathrm{nAChR}$ antagonist, Dihydro- $\beta$-erythroidine hydrobromide $(\mathrm{DH} \beta \mathrm{E})$; intracellular $\mathrm{Ca}^{2+}$ release blocker, ruthenium red (all from Tocris Bioscience, San Diego, CA); $\beta$-secretase (BACE1) inhibitor, LY2811376 (Selleck Chemicals, Houston, TX). All drugs were prepared as concentrated stock solutions in water, except afatinib, picrotoxin and LY2811376 stock concentrations, which were dissolved in 100\% ethanol, and CGP55845 stock concentration, which was dissolved in DMSO. Final ethanol and DMSO concentration did not exceed 2\%. Nicotine was prepared fresh on each test day and its $\mathrm{pH}$ was adjusted to 7.0-7.2 using $1 \mathrm{~N} \mathrm{NaOH}$. For behavioral studies, nicotine was dissolved in physiological saline and administered intraperitoneally (i.p.) at $0.1 \mathrm{mg} / \mathrm{kg}$ expressed as base. Afatinib was dissolved in physiological saline containing 10\% DMSO and $100 \mathrm{mM}$ Captisol (Captisol, La Jolla, CA) and administered i.p. at $10 \mathrm{mg} / \mathrm{kg}$, as previously described (Turner et al, 2014).

\section{OFC Slices}

Mice were sacrificed and their brains removed and sectioned into $300 \mu \mathrm{m}$-thick coronal slices containing OFC with a Vibratome (VT1200, Leica Biosystems, Buffalo Grove, IL) in an ice-cold artificial cerebrospinal fluid solution (ACSF), in which $\mathrm{NaCl}$ was replaced by an equiosmolar concentration of sucrose. ACSF consisted of $130 \mathrm{mM} \mathrm{NaCl}, 3 \mathrm{mM} \mathrm{KCl}$, $1.25 \mathrm{mM} \mathrm{NaH}_{2} \mathrm{PO}_{4}, 26 \mathrm{mM} \mathrm{NaHCO}_{3}, 10 \mathrm{mM}$ glucose, $1 \mathrm{mM}$ $\mathrm{MgCl}_{2}$, and $2 \mathrm{mM} \mathrm{CaCl}_{2}$ (pH 7.2-7.4 when saturated with $95 \% \mathrm{O}_{2} / 5 \% \mathrm{CO}_{2}$ ). Slices were incubated in ACSF at $32-34{ }^{\circ} \mathrm{C}$ for $30 \mathrm{~min}$ and kept at $22-25^{\circ} \mathrm{C}$ thereafter, until transfer to the recording chamber. For experiments with ErbB4 or BACE1 inhibition, slices were maintained in ACSF supplemented with afatinib $(10 \mu \mathrm{M})$ or LY2811376 $(25 \mu \mathrm{M})$ for $1 \mathrm{hr}$ prior to recording. The osmolarity of all solutions was 305$315 \mathrm{mOsm}$. Slices were viewed under an upright microscope (Olympus BX51WI, Olympus, Center Valley, PA) with a $\times 10$ objective.

\section{Electrophysiology}

The recording chamber was continuously perfused (1-2 ml/ min) with oxygenated ACSF heated to $32 \pm 1{ }^{\circ} \mathrm{C}$ using an automatic temperature controller (Warner Instruments, Hamden, CT). Recording pipettes were pulled from 
borosilicate glass capillaries (World Precision Instruments, Sarasota, FL) to a resistance of 1-2 M $\Omega$ when filled with ACSF. Stimulation and recording electrodes were both positioned in layer $3 / 5$ of OFC. Field excitatory postsynaptic potentials (fEPSPs) were evoked at current intensity eliciting $50-60 \%$ of the maximal response amplitude, and delivered at $0.05 \mathrm{~Hz}$, through a bipolar tungsten electrode. Stable baseline responses ( $<5 \%$ variability) were acquired for at least $10 \mathrm{~min}$ prior to drug application or induction of LTP. LTP was induced by a train of 100 pulse $(50 \mathrm{~Hz})$ stimuli repeated three times at $10 \mathrm{~s}$ intervals using the minimal current required to elicit a maximal fEPSP response. Other, more typical, LTP protocols (for example, $100 \mathrm{~Hz}$ stimulation) did not elicit a reliable LTP (data not shown). Following LTP induction, fEPSPs were acquired for $60 \mathrm{~min}$ at $0.05 \mathrm{~Hz}$ at baseline stimulus intensity. All recordings were conducted with a Multi-Clamp700B amplifier (Molecular Devices, Sunnyvale, CA). Currents were high-pass filtered at $2 \mathrm{kHz}$ and digitized at $20 \mathrm{kHz}$ using a Digidata 1550 acquisition board and pClamp10 software (Molecular Devices). Recorded data were analyzed with Clampfit (Molecular Devices).

\section{RT-PCR}

mRNA was performed on OFC from naïve B6129F1 wildtype and $\mathrm{NRG}^{\text {ska }}$ ( $\mathrm{n}=8$ /group) mice. After sacrifice, OFC were dissected out with tissue punch. Half of the samples were used for mRNA analysis; the other halves were used for protein analysis as previously described (Turner et al, 2014). For RT-PCR experiment, first, RNA was isolated using the RNeasy mini kit (Qiagen, Valencia, CA). Then cDNA was synthesized and SYBR-green RT-PCR reactions were assembled using Maxima SYBR Green qPCR Master Mix (Thermo Fisher Scientific, Waltham, MA) along with $5 \mu \mathrm{M}$ primers (final concentration). The mRNA levels of NRG1, NRG3, ErbB3, ErbB4, $\alpha 4, \beta 2$, and $\alpha 7$ nAChR genes were normalized to the housekeeping gene, hypoxanthine-guanine phosphoribosyltransferase (HPRT). Primer sequences are available upon request.

\section{Western Blots}

Naïve B6129F1 wild-type and NRG3 ${ }^{\text {ska }}$ mice ( $n=8$ /group), or wild-type mice received acute saline or nicotine $(0.1 \mathrm{mg} /$ $\mathrm{kg}$ ) injections (i.p.) $20 \mathrm{~min}$ before sacrifice ( $n=7 /$ group). OFC was dissected out using tissue punches $(2 \mathrm{~mm}$ diameter) and homogenized in $200 \mu \mathrm{l}$ ice-cold extraction buffer containing $50 \mathrm{mM}$ Tris, $1 \mathrm{mM}$ EGTA, $1 \mathrm{mM}$ EDTA, $1 \%$ SDS, and $1 \mathrm{mM}$ PMSF ( $\mathrm{pH} 7.4$ ). Protein concentrations were determined using a BCA assay, with bovine serum albumin as the standard. Prior to loading, $6 \times$ SDS Sample buffer (50 mM Tris, 2.5\% SDS, 36\% glycerol, $0.03 \%$ bromophenol blue and 1 M DTT) was added to each sample, which were then boiled for $5 \mathrm{~min}$. Equivalent amounts of protein $(30 \mu \mathrm{g})$ were resolved in Any $\mathrm{kD}$ TGX precast protein gels (Bio-Rad, Hercules, CA) and transferred to nitrocellulose membranes. Membranes were first incubated with LICOR blocking buffer (LI-COR, Lincoln, NE) for $1 \mathrm{~h}$ at RT, then probed with primary antibodies NRG3 (1:1000, Abgent, San Diego CA), ErbB4 (1:2500, a gift from Dr Andres Buonanno at NIH), p-PI3K p85-Tyr458, PI3K p85 (all
1:1000; Cell signaling, Beverly, MA), $\beta$-tubulin (1:2000, BD biosciences, San Jose, CA), and GAPDH (1:4000, Santa Cruz, Dallas, TX) overnight at $4{ }^{\circ} \mathrm{C}$. After washing in PBS, the blots were incubated in correspondent fluorescent secondary antibodies $(1: 10,000$ or $1: 20,000$, LI-COR, Lincoln, NE) in LI-COR blocking buffer for $2 \mathrm{~h}$ at RT. Membranes were then washed and immunolabeling signals were detected using Odyssey SA system (LI-COR, Lincoln, NE). Densitometry measurements were performed using the Image Studio software (LI-COR, Lincoln, NE). Protein levels of NRG3 or ErbB4 were normalized to GAPDH or $\beta$-tubulin, and protein levels of p-PI3K (p85-Tyr458) were normalized to total PI3K (p85) protein.

\section{$\left[{ }^{3} \mathrm{H}\right]$ GABA Release and Uptake Assay}

Mice were sacrificed and frontal cortex dissected out by hand and chopped into $\sim 0.2 \mathrm{~mm}$ cubes using razor blades. Tissue was evenly divided and pre-incubated in oxygenated ACSF for $30 \mathrm{~min}$ at $37^{\circ} \mathrm{C}$. Aminooxyacetic acid (0.1 mM), a GABA transaminase inhibitor, and $\beta$-alanine $(1 \mathrm{mM})$, a glial GABA uptake inhibitor, were present in all solutions.

For GABA release, tissue was incubated in $50 \mathrm{nM}\left[{ }^{3} \mathrm{H}\right]$ GABA (PerkinElmer Life Sciences, Waltham, MA; $30 \mathrm{Ci}$ / mmol) for $30 \mathrm{~min}$ at $37^{\circ} \mathrm{C}$. After a triple wash with ACSF, basal $\left[{ }^{3} \mathrm{H}\right] \mathrm{GABA}$ release was measured for $15 \mathrm{~min}$ in fresh $3 \mathrm{ml}$ ACSF medium every $5 \mathrm{~min}$. Nicotine-evoked $\left[{ }^{3} \mathrm{H}\right]$ GABA release, was measured following a 15 min incubation in ACSF containing 0,1 , or $100 \mu \mathrm{M}$ nicotine. Depolarizationevoked $\left[{ }^{3} \mathrm{H}\right] \mathrm{GABA}$ release was measured during incubation in ACSF containing $20 \mathrm{mM} \mathrm{KCl}$ for $30 \mathrm{~min}$. At the end of all release assays, brain tissue was lysed by incubation in $0.2 \mathrm{~N}$ $\mathrm{HCl}$ for $45 \mathrm{~min}$. The medium was collected and residual $\left[{ }^{3} \mathrm{H}\right]$ GABA levels measured. The sum of basal, evoked, and residual radiation levels was assumed to represent $100 \%$ of total $\left[{ }^{3} \mathrm{H}\right] \mathrm{GABA}$ content.

For GABA uptake, tissue was incubated in ACSF in the presence or absence of nicotine $(1 \mu \mathrm{M})$ for $30 \mathrm{~min}$ at $37^{\circ} \mathrm{C}$. Then, ACSF containing $400 \mathrm{nM}\left[{ }^{3} \mathrm{H}\right] \mathrm{GABA}$ was added for 2 min at either $37^{\circ} \mathrm{C}$ (total $\left[{ }^{3} \mathrm{H}\right] \mathrm{GABA}$ uptake) or $0{ }^{\circ} \mathrm{C}$ (nonspecific $\left[{ }^{3} \mathrm{H}\right] \mathrm{GABA}$ uptake). To terminate the assay, slices were washed three times with ice-cold ACSF. Tissue was lysed by incubation with $\mathrm{NaOH}(0.1 \mathrm{~N})$ for $30 \mathrm{~min}$. Total protein concentrations of the samples were measured using a BCA protein assay kit (Thermo Fisher Scientific, Waltham, MA). Specific $\left[{ }^{3} \mathrm{H}\right]$ GABA uptake was determined by subtracting the non-specific from the total $\left[{ }^{3} \mathrm{H}\right] \mathrm{GABA}$ uptake and normalized to the total protein concentration.

\section{Operant Chambers}

Mouse operant conditioning chambers (MED Associates; St Albans, VT, USA) were equipped with a standard grid floor and house light $(28 \mathrm{~V}, 100 \mathrm{~mA})$, a central reward port attached to a fluid dipper, and two ultra-sensitive retractable levers positioned on the left and right sides of the chamber with large cue lights $(2.5 \mathrm{~cm} ; 28 \mathrm{~V}, 100 \mathrm{mV})$ above each lever. All events, including light presentation, lever operations, and reward delivery, were controlled by a SmrtCtrl interface running MED-PC IV software on a Dell PC (Optiplex 960). All operant boxes were equipped with a video tracking system consisting of HD cameras (960H/700TVL) connected 
to an 8-channel HD Analog DVR system (Q-See, Anaheim, CA).

\section{Go/no-go Visual Discrimination Task}

The operant go/no-go visual discrimination task was designed to assess attention and impulse control under conditions of response conflict in mice. This procedure was adapted from operant tasks previously used (Gubner et al, 2010; Harrison et al, 1999; Kolokotroni et al, 2011; McDonald et al, 1998). Briefly, water-restricted animals were autoshaped on a fixed-ratio 2 (FR 2) schedule of reinforcement to lever press for water sweetened with a calorie-free sweetener saccharin $(0.066 \% ; 10 \mu \mathrm{l})$. The concentration of saccharin was based on previous studies assessing instrumental and consummatory behaviors in mice (Ben Hamida et al, 2013; Olive et al, 2003; Ortega et al, 2013). After attaining at least 30 lever press responses within a $30-\mathrm{min}$ session for three consecutive days, animals were advanced to a pre-training phase as described previously (Cole et al, 2015; D'Amore et al, 2013; Ortega et al, 2013). During this phase, the animals were required to press the active lever within $10 \mathrm{~s}$ to get the reward. To control for any novelty effects associated with the visual stimulus during the go/no-go phase of training (see description below), trials were randomly associated with unpredictably occurring visual stimuli (presented only in 50\% of trials) that involved illumination of the panel light for $10 \mathrm{~s}$ above the lever during the pre-training phase.

Mice that attained the pre-training criterion (30 rewards and $\leq 10 \%$ omissions for three consecutive days) were moved to the go/no-go phase where they were required to discriminate between response cues (go trials) and withholding cues (no-go trials), respectively. A session began with illumination of the house light followed by 48 trials ( 24 go and 24 no-go trials) with an ITI of $9 \pm 3 \mathrm{~s}$. Go trials consisted of the presentation of a continuous illumination of a $7 \mathrm{~s}$ cue light from either the left or the right panel, followed by the presentation of both levers $2 \mathrm{~s}$ later. Levers were presented for $5 \mathrm{~s}$ and co-terminated with the cue light. Two lever press responses (FR 2) on the cued lever were scored as a 'hit' and were followed by reward (sweetened water) delivery. Failure to respond on the go trial resulted in a timeout phase during which the house light was extinguished for $10 \mathrm{~s}$, and which counted as an 'omission error'. No-go trials consisted of a flashing $(2 \mathrm{~Hz})$ cue light from either the right or left panel. As with the go trials, both levers were presented $2 \mathrm{~s}$ later and co-terminated with the flashing cue after $5 \mathrm{~s}$. Two responses on any lever during the no-go trials resulted in a timeout phase (no reward). These responses represented commission errors and were labeled as 'false alarms'. To obtain a reward during the no-go trials animals were required to withhold lever responding to cue presentations. Presentation of continuous or flashing cues was pseudorandomized in each session. Single responses on any lever during all trial types were not scored and allowed the animal an opportunity to either withhold or continue lever pressing. Two lever presses on a non-cued lever in either go or no-go trials were scored as never-reinforced errors. Animals were considered to have achieved performance criterion after three consecutive days of $\geq 70 \%$ correct responding on all trials.
After attaining performance criterion, each mouse underwent four tests in a counterbalanced order: vehicle+saline (veh+sal), saline+afatinib (sal+afat), vehicle+nicotine (veh + nic), and nicotine+afatinib (nic+afat). Afatinib (10 mg/kg) or vehicle was given $20 \mathrm{~min}$ prior to behavioral testing. Acute nicotine $(0.36 \mathrm{mg} / \mathrm{kg})$ or saline was injected $10 \mathrm{~min}$ prior to behavioral testing sessions. Between tests, mice underwent at least 5-days of washout period during which no injections were given, but behavior monitored to make sure that performance criterion was maintained/re-established.

The number of hits, false alarms, omission errors, neverreinforced errors, and response latencies were obtained for each test. Data for go and no-go trial performance was expressed as the probability of hits ( $p$ (hits)), calculated as percent of correct responses in go trials and probability of false alarms $(\mathrm{p}(\mathrm{fa}))$, calculated as percent of incorrect responding in no-go trials. Sensitivity index (SI) served as a measure of attention and discriminability, and was calculated using the formula $[p($ hit $)-p(f a)] /[2(p$ (hit $)+p$ $(\mathrm{fa}))]-[\mathrm{p}(\mathrm{hit})+p(\mathrm{fa})]^{2}$ as described previously (McDonald et al, 1998; McGaughy and Sarter, 1995). The ratio of number of rewards earned to the total number of responses in the go trials served as a measure of efficiency (Gubner et al, 2010).

\section{Statistics for Murine Experiments}

One-way ANOVAs with Bonferroni's post hoc tests or Student's $t$-tests were used to analyze electrophysiology data. Student's $t$-tests were used to analyze protein expression and GABA uptake. Repeated one-way ANOVAs with Fisher's LSD post hoc tests were used to analyze GABA release and all behavioral data. All data are presented as the mean \pm SEM and $\alpha$ was set at $p<0.05$.

\section{RESULTS}

\section{Nicotine and NRG3 Modulate Long-Term Plasticity in the OFC}

We began by evaluating the effects of nicotine and NRG3 on long-term synaptic plasticity in the OFC. Under control conditions, a $50 \mathrm{~Hz}$ stimulation protocol resulted in $15 \%$ potentiation of fEPSPs evoked in OFC layer 3/5 (Figure 1a and e) that lasted up to $60 \mathrm{~min}$ of recording. In the presence of nicotine $(1 \mu \mathrm{M})$, we observed a pronounced conversion of this long-term potentiation (LTP) to long-term depression (LTD). Nicotine reduced fEPSP amplitudes to about $60 \%$ of baseline values (Figure 1a and e). Application of NRG3 $(2 \mathrm{nM})$ had a very similar effect at steady-state levels, although short-term depression during the first 5 min after the induction protocol was less pronounced than after nicotine (Figure 1a and e). LTP induced in control conditions could be completely blocked by the NMDA receptor antagonist, DL-AP5 $(50 \mu \mathrm{M})$ with short-term effects similar to nicotine and NRG3 (Figure 1b). However, DL-AP5 did not block either nicotine- or NRG3-induced conversion of LTP to LTD (Figure 1b). These results indicate that acute application of either nicotine or NRG3 can strongly regulate the direction of long-term plasticity in the OFC and that this regulation is independent of NMDA receptor activation. 
a

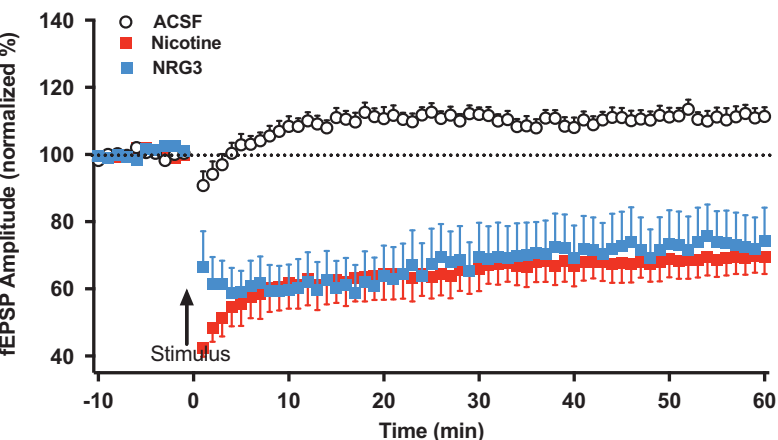

C
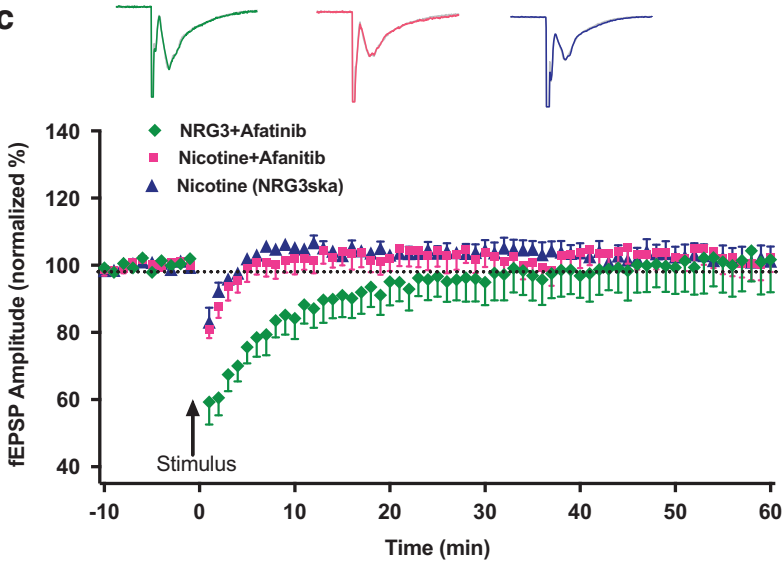

e

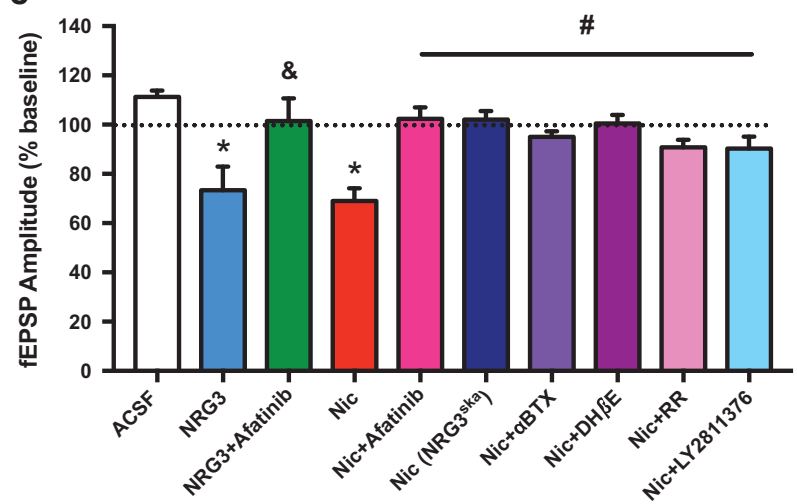

b

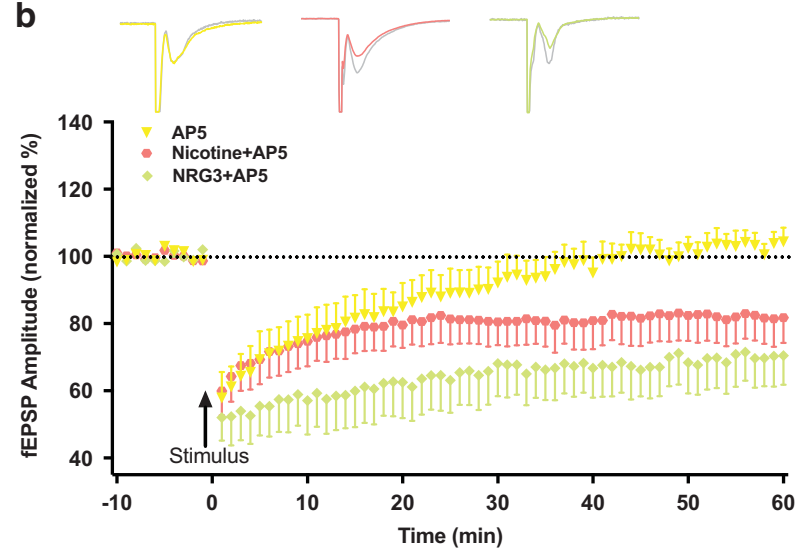

d
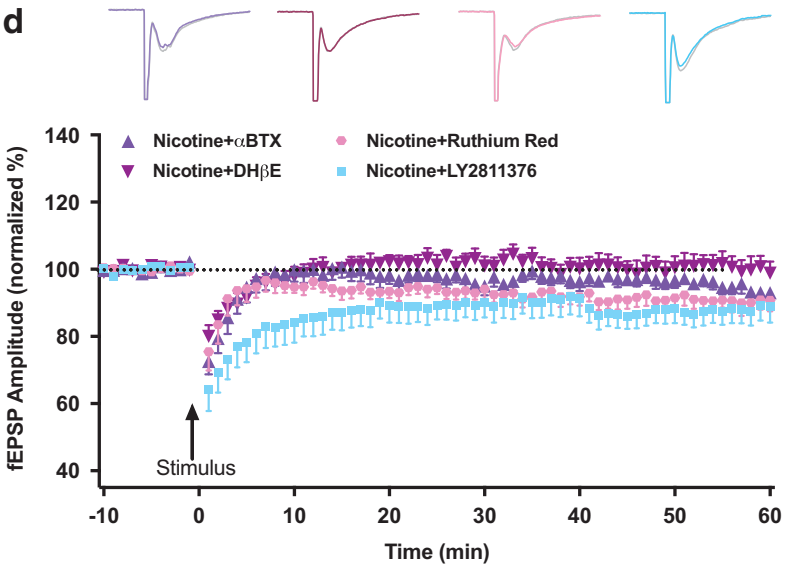

Treatment

Figure I Nicotine effects on OFC neuroplasticity rely on NRG3/ErbB4 signaling. (a) A stimulation protocol, inducing LTP in control (ACSF) conditions results in LTD in the presence of NRG3 (2 nM) or nicotine (I MM) (ACSF: $n=12$ slices, 5 mice; NRG3: $n=6$ slices, 3 mice; nicotine: $n=7$ slices, 3 mice). (b)

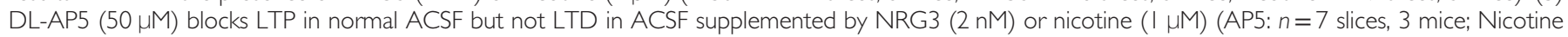
+AP5: $n=6$ slices, 3 mice; NRG3+AP5: $n=8$ slices, 3 mice). (c) ErbB4 inhibitor afatinib (I0 MM) attenuated both nicotine- and neuregulin induced LTD (NRG3+afatinib: $n=6$ slices, 3 mice; nicotine+afatinib: $n=7$ slices, 3 mice). Nicotine-induced LTD is also attenuated in a strain of NRG3 $3^{\text {ska }}$ mice that express reduced NRG3 levels (Nicotine (NRG3 ${ }^{\text {ska }}$ ): $n=7$ slices, 3 mice). (d) Nicotine-induced LTD was attenuated by $\alpha 7 n A C h R s$ antagonist, $\alpha B T X$ (I00 $\mu M$ );

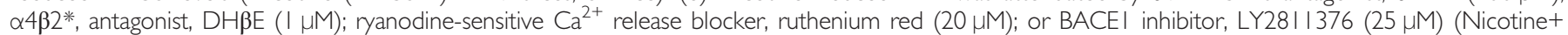
$\alpha B T X: n=7$ slices, 3 mice; Nicotine+DH $\beta E$ : $n=6$ slices, 3 mice; Nicotine+ruthenium red: $n=8$ slices, 3 mice; Nicotine+LY28II 376: $n=9$ slices, 4 mice). (e) fEPSP amplitudes in the last 10 min of recordings for treatment groups in a-d. Data are presented as mean \pm SEM. Data are analyzed by one-way ANOVAs followed by Bonferroni's post hoc tests, or Student's t-test. ${ }^{*} p<0.05$ vs ACSF; ${ }^{*} p<0.05$ vs NRG3; ${ }^{\#} p<0.05$ vs nicotine.

\section{Nicotine Activates NRG3-ErbB4 Signaling}

Some behavioral and molecular effects of nicotine have been shown to rely upon NRG3 signaling (Turner et al, 2014). Therefore, to ascertain that NRG3 effects are mediated by activation of its ErbB4 receptor in the OFC, we pre-incubated slices with ErbB4 antagonist afatinib (10 $\mu \mathrm{M}, 1 \mathrm{~h}$ incubation). Results showed that afatinib attenuated the short-term effect and completely occluded the steady-state effect of nicotine 
on LTP in the OFC $\left(F_{(9,67)}=7.70, p<0.0001\right.$; post hoc: $p<0.0001$; Figure 1c and e). To further strengthen the link between nicotine and NRG3 signaling, we examined nicotine-induced plasticity in NRG3 scaramanga mice $\left(\mathrm{NRG}^{\mathrm{ska}}\right)$. These mice possess a naturally occurring microsatellite repeat in exon 7 of NRG3, resulting in reduced expression of NRG3 protein (mRNA levels failed to reach statistical significance), but elevated expression of ErbB4 mRNA (protein levels failed to reach statistical significance) in the OFC (Figure 2a and b). Similar to the results seen with afatinib, nicotine-induced conversion of LTP was absent in $\mathrm{NRG}^{\text {ska }}$ mice $\left(F_{(9,67)}=7.70, p<0.0001\right.$; post hoc: $p<0.001$; Figure $1 \mathrm{c}$ and $\mathrm{e}$ ), confirming the involvement of NRG3 (despite of unchanged ErbB4 protein levels) in nicotine action. This indicates that in mice with reduced NRG3 expression, nicotine was unable to elicit significant signaling via NRG3 to the ErbB4 receptor, despite normal ErbB4 protein levels. These results together suggest that nicotine regulates long-term plasticity in the OFC via activation of the NRG3-ErbB4 signaling pathway. These results are supported by the lack of compensatory regulation of NRG1, ErbB3, or nAChR subunits in the OFC of NRG3 ${ }^{\text {ska }}$ mice (Figure $2 \mathrm{c}$ and $\mathrm{d})$.
NRG3 is a membrane-anchored protein that is released into extracellular space by cytosolic $\mathrm{Ca}^{2+}$-dependent BACE1mediated cleavage (Hu et al, 2008; Ma et al, 2007). Nicotine is believed to mediate $\mathrm{Ca}^{2+}$ influx through activation of homomeric $\alpha 7$ and heteromeric $\alpha 4 \beta 2^{*}$ nicotinic receptor (nAChR) subtypes, both of which are enriched in the frontal cortex (Dickinson et al, 2008; Poorthuis et al, 2013; Rousseau et al, 2005). Therefore, we tested the effects of $\alpha 7 \mathrm{nAChR}$ antagonist, $\alpha$-bungarotoxin $(\alpha \mathrm{BTX}, 100 \mu \mathrm{M})$ and $\alpha 4 \beta 2^{*}$ antagonist, dihydro- $\beta$-erythroidine $(\mathrm{DH} \beta \mathrm{E}, 1 \mu \mathrm{M})$ on nicotine-induced synaptic plasticity. Both antagonists attenuated nicotine-induced LTD with a slightly stronger effect of $\mathrm{DH} \beta \mathrm{E}$, indicating that both receptor subtypes are involved in nicotine effects on OFC plasticity (Figure $1 \mathrm{~d}$ and e). We investigated whether nicotine regulation of OFC plasticity depended on release of $\mathrm{Ca}^{2+}$ from intracellular stores (Dickinson et al, 2008; Rousseau et al, 2005). Following incubation with a ryanodine receptor blocker, ruthenium red $(20 \mu \mathrm{M})$, we observed a significant attenuation, but not a complete rescue, of nicotine-induced plasticity, indicating involvement of both $\mathrm{Ca}^{2+}$ influx through nAChRs and $\mathrm{Ca}^{2+}-$ dependent $\mathrm{Ca}^{2+}$ release from ryanodine receptor-sensitive stores (Figure 1d and e). Finally, we investigated whether extracellular nicotine triggers $\mathrm{Ca}^{2+}$-dependent $\mathrm{BACE} 1$ a

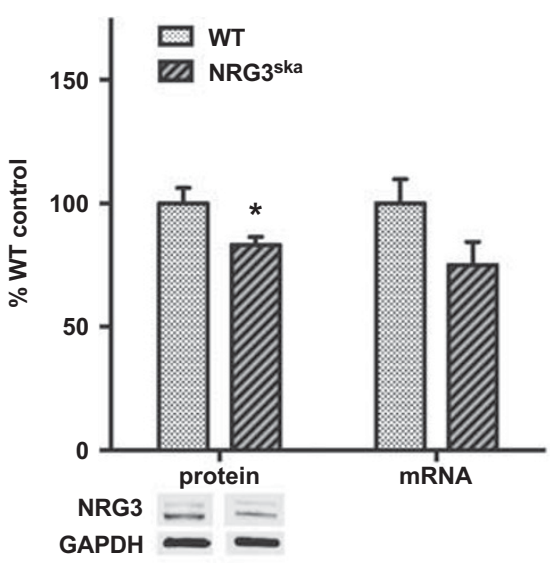

C

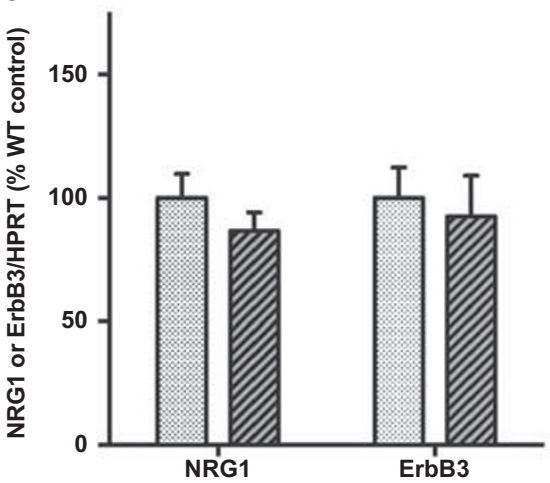

b

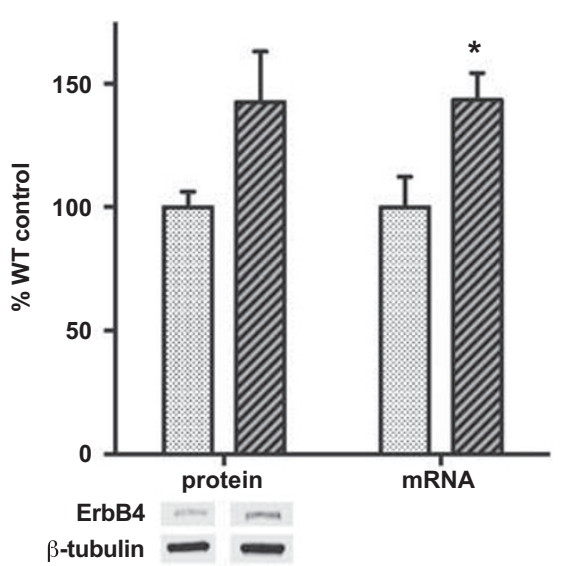

d

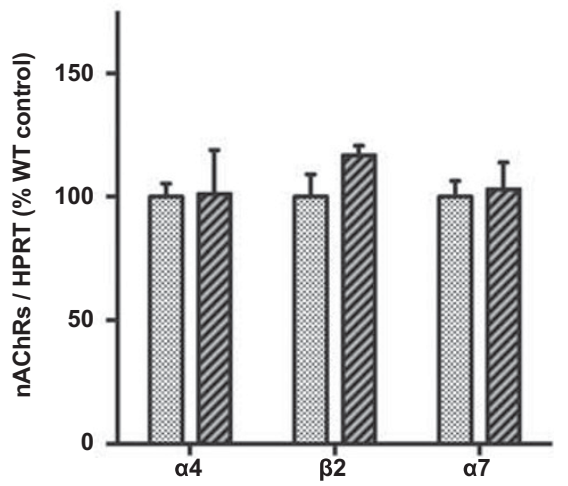

Figure 2 Molecular changes in the OFC of NRG3 $3^{\text {ska }}$ mice. (a) NRG $3^{\text {ska }}$ mice have reduced expression of NRG3 protein in the OFC compared to wild type controls. (b) ErbB4 mRNA is increased in the OFC of NRG3 $3^{\text {ska }}$ mice. (c) NRGI and ErbB3 mRNA levels are similar in WT and NRG3 ${ }^{\text {ska }}$ mice. (d) The expression of $n A C h R s$ mRNA is unchanged in the NRG ${ }^{\text {ska }}$ mice. Protein levels of NRG3 or ErbB4 were normalized to GAPDH or $\beta$-tubulin, then normalized to WT controls. mRNA levels are normalized to WT controls. Data are presented as mean \pm SEM. $n=8$ for both WT and NRG3 ${ }^{\text {ska }}$ mice. Data are analyzed by Student's t-tests. $*$ $p<0.05$ compared to WT. 
activity, a required enzymatic step in NRG3 cleavage. Preincubation of OFC slices with BACE1 inhibitor, LY2811376 $(25 \mu \mathrm{M})$ significantly attenuated, but did not completely block, nicotine-induced plasticity (Figure 1d and e).

\section{Nicotine/NRG3/ErbB4-mediated Plasticity Depends on GABA Signaling}

ErbB4 receptors are expressed by GABAergic interneurons throughout the brain (Bean et al, 2014), and may modulate GABAergic activity via PI3-kinase signaling (Hatakeyama et al, 2003). We confirmed that nicotine treatment activates PI3 kinase in the OFC $\left(t_{12}=2.53, p<0.05\right.$; Figure $\left.3 a\right)$ and examined whether nicotine exposure affects GABA uptake or release levels. Our results showed that application of nicotine $(1 \mu \mathrm{M}$ or $100 \mu \mathrm{M})$ did not alter release of $\left[{ }^{3} \mathrm{H}\right] \mathrm{GABA}$ at baseline or following potassium-induced depolarization (Figure 3b). On the other hand, GABA uptake was significantly increased upon nicotine application $\left(t_{8}=2.87\right.$, $p<0.05$; Figure $3 \mathrm{c}$ ), likely resulting in elevated vesicular GABA content (Ortinski et al, 2006). To evaluate the contribution of GABAergic inhibition on nicotine-induced plasticity, we pre-incubated OFC slices with picrotoxin $(100 \mu \mathrm{M})$ and CGP55845 $(1 \mu \mathrm{M}), \mathrm{GABA}_{\mathrm{A}}$ and $\mathrm{GABA}_{\mathrm{B}}$ antagonists, respectively. Blockade of GABA receptormediated signaling completely restored LTP observed under control conditions $\left(t_{12}=7.13, p<0.0001\right.$; Figure $3 \mathrm{~d}$ and e). We conclude that $\mathrm{nAChR}$ activation in the OFC stimulates NRG3/ErbB4 signaling to promote an increase in GABAergic signaling and conversion of OFC LTP to LTD.

\section{NRG3-ErbB4 Signaling Leads to Deficits in Attentional Control}

Attention and impulse control deficits are hallmark features of nicotine addiction (Baker et al, 2012). To examine whether dysregulated NRG3-ErbB4 signaling may underlie these phenotypes, we evaluated the effects of ErbB4 inhibition during nicotine administration on cognitive flexibility using a go/no-go discrimination task. This task has been shown to evaluate both attention and impulsivity controlled by the larger striato-thalamo-orbitofrontal circuit (Eagle and Baunez, 2010; Tremblay and Schultz, 2000). We found a significant treatment effect on sensitivity index (SI), a cumulative measure of attention and discriminability (see 'Methods'). Nicotine administered $20 \mathrm{~min}$ prior to behavioral testing significantly reduced SI, an effect that was rescued by administration of afatinib $\left(F_{(3,27)}=8.03, \quad p<0.001\right.$; Figure $4 \mathrm{a})$. This finding indicated that acute nicotine impaired stimulus discrimination via ErbB4 signaling. Further analysis conducted by trial type indicated that the effect on SI was primarily driven by go trial performance a

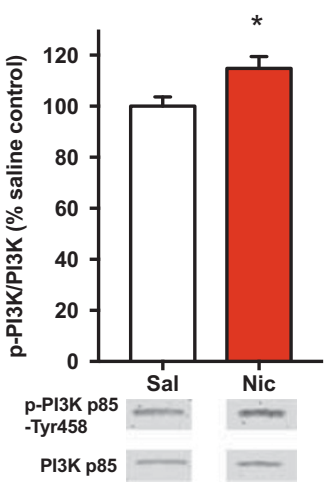

b

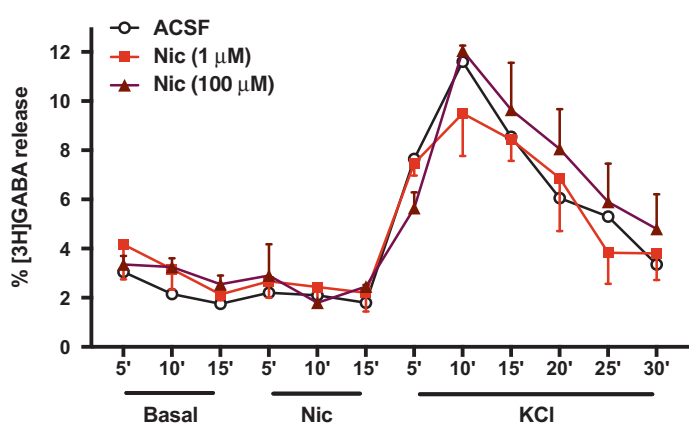

C

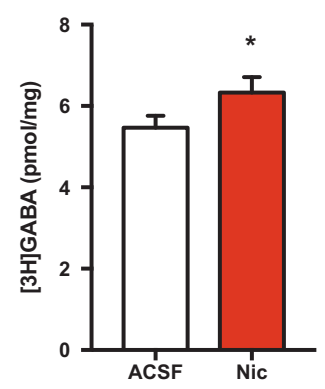

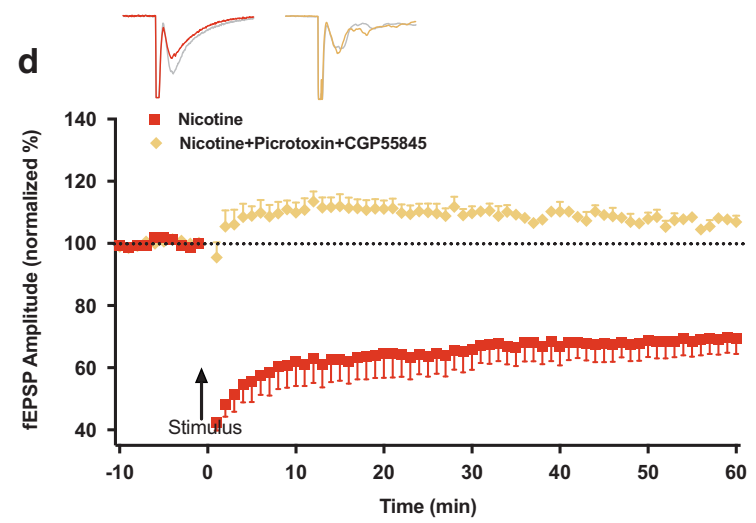

e

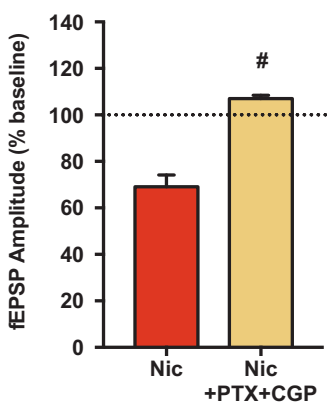

Figure 3 Nicotine regulates GABAergic transmission downstream of ErbB4 signaling in the OFC. (a) Acute nicotine treatment $(0.1 \mathrm{mg} / \mathrm{kg}$, i.p.) increases the phosphorylation of ErbB4 target, PI3K p85 at Tyr458 ( $n=7$ per group). (b) Nicotine ( I HM or I $00 \mu M$ ) fails to alter basal or depolarization-induced GABA release in frontal cortex $(n=2-3$ per group). (c) Nicotine $(I \mu M)$ significantly increases GABA uptake $(n=9)$. ( $($ and e) Co-application of GABA $R$ antagonist, picrotoxin $(I 00 \mu M)$ and GABA $_{B} R$ antagonist, CGP55845 (I HM) completely blocks nicotine-induced conversion of LTP ( $n=7$ slices, 4 mice). Data are presented as mean \pm SEM. Data are analyzed by Student's $t$-tests. ${ }^{*} p<0.05$ vs saline or ACSF; ${ }^{*}<0.05$ vs nicotine. 
a

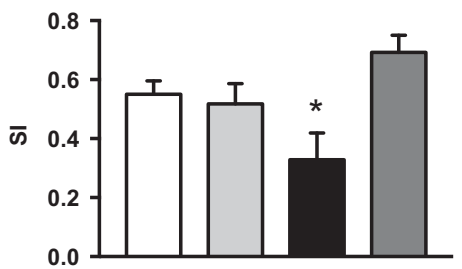

d

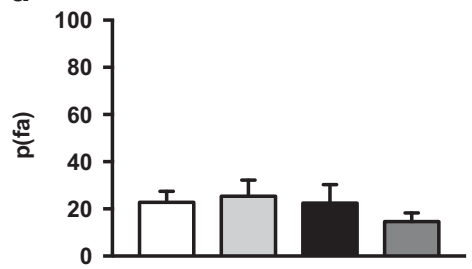

b
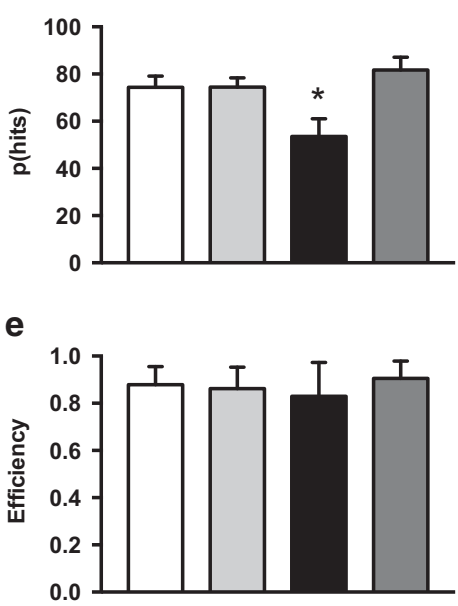

C

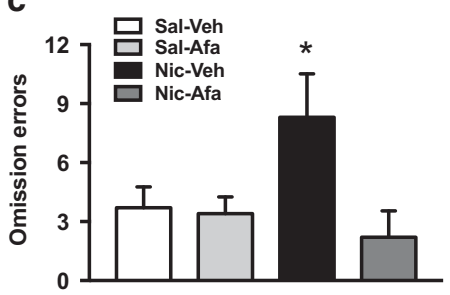

f

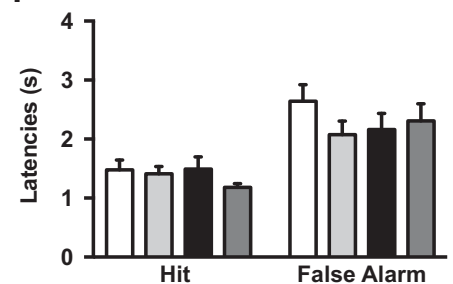

Figure 4 Nicotine-induced impairments in the go/no-go task are sensitive to ErbB4 antagonism. (a) Afatinib rescues nicotine-induced deficits in sensitivity index (SI). (b) Afatinib rescues correct responding on go-trials [percent hits: p(hits)]. (c) Afatinib rescues nicotine-induced increase in omission errors. (d) Incorrect responding on no-go trials [percent false alarms: $p(\mathrm{fa})$ ] is unchanged following nicotine and afatinib treatments. (e) Nicotine and afatinib treatments do not affect the ratio of number of rewards earned to the total number of responses in the go trials (Efficiency). (f) Response latencies for hits and false alarms remain steady between groups. In all panels, $n=10$ per treatment condition. Data are presented as mean \pm SEM. Data are analyzed by one-way repeated measures ANOVAs followed by LSD post hocs. *p $<0.05$ vs veh+sal.

(p(hits)), which, similarly to SI, was reduced by nicotine and rescued by afatinib $\left(F_{(3,27)}=4.47, p<0.01\right.$; Figure $\left.4 \mathrm{~b}\right)$. The incidence of never-reinforced responses to levers not associated with a visual stimulus in this well-practiced task was very low (not shown) and reduction in $\mathrm{p}$ (hits) was due primarily to withholding a response on a go-trial (ie, omission errors), an indicator of attentional bias (see 'Discussion'). Omission errors were significantly increased in the nicotine+vehicle treated group, but not in the nicotine +afatinib treated animals $(F(3,27)=4.04, \quad p=0.017$; Figure 4c). Video analysis showed unchanged reward port visits (Sal+Veh: $0.30 \pm 0.15$; Sal+Afat: $0.20 \pm 0.13$; Nic \pm Veh: $0.40 \pm 0.16$; Nic \pm Afat: $0.10 \pm 0.10$ ), indicating that the omission errors represented withholding of responses on go trials, rather than a general loss of interest in reward. None of the drug treatments affected $\mathrm{p}(\mathrm{fa})$, a measure of impulse control $\left(F_{(3,27)}=1.08, p=0.38\right.$; Figure $\left.4 \mathrm{~d}\right)$. Lastly, we did not observe any changes in the efficiency $\left(F_{(3,27)}=1.0\right.$, $p=0.41$; Figure $4 \mathrm{e}$ ) or response latencies for hits and false alarms (both $p>0.300$; Figure $4 \mathrm{f}$ ), indicating that omission error changes following nicotine were not due to general motor impairment. These findings indicate that nicotinemediated ErbB4 signaling interferes with attentional control, but not impulsivity-associated processes.

\section{DISCUSSION}

The OFC regulates impulsivity, affective value of reinforcers and emotion-attention interactions (Hartikainen, 2003; Kringelbach, 2005; Torregrossa et al, 2008) with implications for the study of substance use disorders (Schoenbaum et al, 2016), including nicotine dependence. Previous studies reported that nicotine self-administration in rodents alters synaptic morphology in the OFC (Vazquez-Sanroman et al, 2016), while tobacco smokers display both morphological and functional connectivity changes within this region
(Claus et al, 2013; Li et al, 2015). Our study provides the first evidence that $\mathrm{nAChR}$ activity gates the direction of longterm plasticity in the OFC via NRG3-ErbB4 signaling. Nicotine mediated conversion of LTP to LTD represents a form of 'metaplasticity' that may contribute to the NRG3/ ErbB4 dependent behavioral effects of nicotine in the OFC, as we show in the go/no go task.

Nicotine signaling through $\mathrm{nAChRs}$ has divergent effects on neuronal plasticity. For example, previous studies show that both $\alpha 4 \beta 2^{*}$ and $\alpha 7 \mathrm{nAChR}$ activation can either potentiate (Lagostena et al, 2008; Tang and Dani, 2009; Welsby et al, 2009) or prevent (Alkondon and Albuquerque, 2001; Alkondon et al, 1997; Ji et al, 2001) LTP induction in hippocampus, with variable effects attributed to activation of specific interneuron populations. We observe that nicotinic stimulation in the OFC not only prevents induction of LTP, but also changes the sign of plasticity to result in a profound LTD (Figure 1a/e). While $\alpha 4 \beta 2^{*}$ and $\alpha 7$ nAChRs are expressed in the OFC (Cloke and Winters, 2015; Mendez et al, 2013), their specific localization is not clear. In the PFC, $\alpha 4 \beta 2^{*}$ and $\alpha 7$ nAChRs have been shown to be expressed by both GABAergic interneurons as well as pyramidal neurons (Poorthuis et al, 2013). Our studies with nAChR subtype selective antagonists confirmed that both $\alpha 4 \beta 2^{\star}$ and $\alpha 7$ nAChRs contribute to nicotine-induced effects on synaptic plasticity in the OFC.

Activation of $\alpha 7$ or $\alpha 4 \beta 2^{*}$ nAChRs increases intracellular $\mathrm{Ca}^{2+}$ concentration, although by different mechanisms (Dickinson et al, 2008; Rousseau et al, 2005). Our pharmacological experiments indicate that nicotinemediated effects on OFC plasticity involve release of $\mathrm{Ca}^{2+}$ from intracellular stores. While $\mathrm{Ca}^{2+}$ can regulate many synaptic processes, $\mathrm{Ca}^{2+}$-induced activation of BACE1 has been shown to dramatically impact both LTP expression and LTP-associated behaviors (Ma et al, 2007). Our data suggest that BACE1 activation by $\mathrm{Ca}^{2+}$ derived from intracellular 


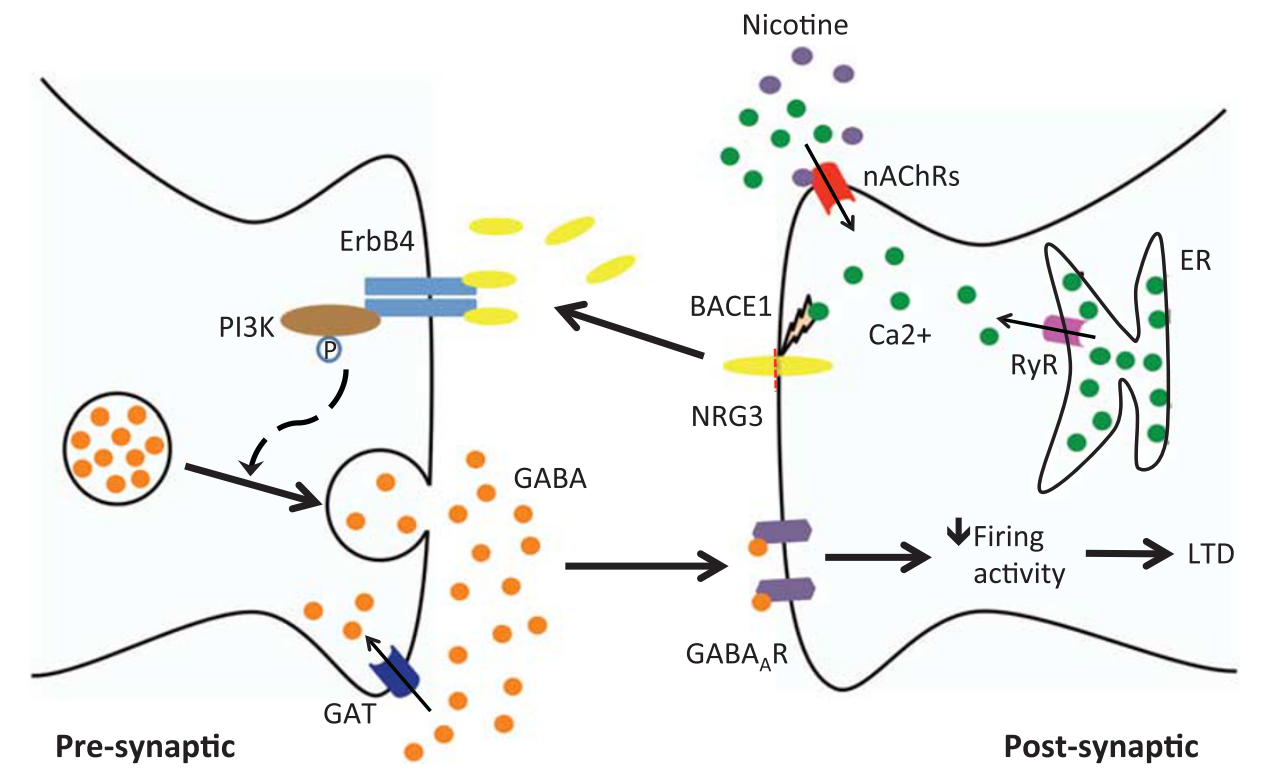

Figure 5 A proposed model for nicotine-induced synaptic plasticity in the OFC. Nicotine activates $\mathrm{Ca}^{2+}$-permeable nAChRs, and Ca ${ }^{2+}$-sensitive ryanodine receptors (RyR). Increased intracellular $\mathrm{Ca}^{2+}$ enhances the proteolytic activity of BACEI, which directly cleaves NRG3. NRG3 binds to ErbB4 and increases GABA release. Nicotine also increases GABA uptake, presumably via an ErbB4-independent pathway. Increased vesicular GABA coupled with ErbB4facilitated GABA release decreases excitability of post-synaptic pyramidal neurons and promotes LTD.

stores and $\mathrm{Ca}^{2+}$-permeable nAChRs promotes conversion of OFC LTP to LTD by nicotine (Figure 1d and e). While we demonstrate that BACE1 activation triggers NRG3 signaling, the identity of other molecular targets downstream of BACE1 signaling remains undefined.

Separate studies have demonstrated that ErbB4 expression is prominently localized to OFC GABAergic interneurons (Bean et al, 2014) and that nicotine regulation of synaptic plasticity in the prefrontal cortex involves enhanced GABAergic transmission (Couey et al, 2007). Our results suggest a model by which nAChR signaling induces NRG3 cleavage via BACE1, to promote activation of ErbB4 receptors located on GABAergic interneurons with effects on long-term synaptic plasticity (Figure 5). The contrast between complete inhibition of nicotine effects by ErbB4 and partial inhibition by BACE1 antagonist supports the evidence that mechanisms other than proteolytic cleavage of NRG3 by BACE1 can promote ErbB4 activation by nicotine (Vullhorst et al, 2015). Antagonists of both nAChRs and ErbB4 receptors eliminated nicotine-associated depression of fEPSPs in the OFC, but were unable to restore synaptic potentiation. Full recovery of LTP was observed only after treatment with GABA receptor antagonists, suggesting that nicotine-dependent plasticity in the OFC involves both ErbB4-dependent and ErbB4-independent components. The latter may reflect contribution of GABA released in response to interneuron depolarization by presynaptic nAChRs.

Nicotine has been shown to increase both spontaneous and evoked GABA release using whole-cell recordings (Bianchi et al, 1995; Kofalvi et al, 2000). While we saw a significant increase in $\left[{ }^{3} \mathrm{H}\right] \mathrm{GABA}$ uptake following nicotine application (Figure 3c), we report no change in either basal or $\mathrm{KCl}$-induced GABA release after nicotine application using $\left[{ }^{3} \mathrm{H}\right] \mathrm{GABA}$ release assays (Figure $3 \mathrm{~b}$ ). This discrepancy could be due to differences in temporal resolution of the two approaches. For example, $\left[{ }^{3} \mathrm{H}\right]$-based analyses report pooled neurotransmitter concentrations over time scales that are substantially longer than those involved in electrophysiological responses. Alternatively, $\left[{ }^{3} \mathrm{H}\right] \mathrm{GABA}$ release assays may be more effective at capturing fluctuations in ambient, but not synaptic GABA concentrations reported by electrophysiological assays. In our experiments, increased $\left[{ }^{3} \mathrm{H}\right] \mathrm{GABA}$ uptake is likely to result in increased vesicular GABA content and increased synaptic, but not ambient GABA concentrations.

In conjunction with alterations in OFC plasticity, we find evidence that nicotine-induced activation of the NRG3/ ErbB4 pathway impacts behavioral performance relevant to OFC-mediated executive function. Acute nicotine impaired measures of attention, but not impulse control/response inhibition in the go/no-go discrimination task and this effect could be reversed by pharmacologic inhibition of ErbB4 signaling. The effects of acute nicotine on impulsive responding that we observe are inconsistent with studies that report increased behavioral disinhibition and those that report negligible nicotine effects (Day et al, 2007; Hahn et al, 2003; Kirshenbaum et al, 2011; Kolokotroni et al, 2011; Stolerman et al, 2000). This could be due to differences in nicotine dose, specific behavioral procedures used (5-choice serial reaction time task, differential reinforcement of low rates of behavior, go/no-go procedure, stop-signal task), and the species involved. Additionally, effects of acute nicotine could be more prominent for some aspects of impulsivity such as impulsive choice behavior (Kolokotroni et al, 2011), but not others, such as impulsive action evaluated by the go/ no-go task that we employed.

Reduced SI observed with acute nicotine in our study was primarily associated with reduced hits and high omission errors during go-trials. Because in a well-practiced task, it is 
rare that animals will respond to a lever not associated with a visual stimulus (see 'Results'; the incidence of neverreinforced errors was very low), these data indicate that acute nicotine affected the animals' optimal decision strategy to perform the task. Omission errors in a go/no-go task reflect high attention to losses (Yechiam et al, 2006). Therefore, nicotine treatment may increase bias towards the blinking cue (no-go trial) to avoid punishment, resulting in adoption of a more conservative strategy of withholding responses on go trials leading to higher omission errors. Anxiety is commonly associated with cognitive bias and affects cognitive strategies to make optimal choices (Hartley and Phelps, 2012). Thus, it is plausible that attentional bias towards no-go trials might have occurred due to anxiogenic effects of acute nicotine while amelioration of cognitive deficits by afatinib occurred due to the interruption of ErbB4-mediated anxiogenesis. Previous studies from our lab have shown that transcriptional regulation of NRG3-ErbB4 signaling regulates behavioral symptoms of anxiety induced by nicotine withdrawal (Turner et al, 2014). This is consistent with epidemiological studies suggesting that nicotine dependence increases the risk of anxiety disorders and panic attacks (Bruijnzeel, 2012). Frontocortical activation, including OFC, has been implicated in processing anxiety and anxiety-dependent cognitive traits of attention and impulsivity, all of which are strongly dysregulated in nicotine dependence (Gold et al, 2015; Rauch et al, 2007; Ursu and Carter, 2009). Additionally, patients with OFC damage display deficits in attentional control specifically in response to emotional stimuli (Hartikainen et al, 2012; MakiMarttunen et al, 2017). Thus, nicotine-induced alterations in OFC neuronal plasticity together with activity in associated corticolimbic structures (eg, hippocampus, amygdala) that are engaged in affective decision processes, might contribute to anxiety-related cognitive bias towards no-go signals. A potential limitation of this study is that afatinib was given systemically and this may have produced pharmacological inhibition of ErbB4 receptors throughout the brain. Therefore, we could not rule out the possibility that NRG3 signaling in brain regions other than OFC might also have contributed to the observed behavioral effects. Further studies employing experimental approaches to regionally target ErbB4 receptors are warranted to establish that nicotine-induced alterations in executive functions are causally linked to modulation of NRG3 signaling in the OFC.

Elevated levels of NRG3 have previously been shown to impact affective behaviors in mice (Turner et al 2014). Interestingly, increased NRG3 expression due to genetic variation was recently observed in patients with affective disorders (Paterson et al, 2017). These increased NRG3 protein levels in human prefrontal cortex have been attributed to the intronic NRG3 single nucleotide polymorphism (SNP) rs10728842 positioned proximally to an alternative promoter and transcription start site (Kao et al, 2010). This same SNP has also been shown to correlate with significantly reduced human prefrontal cortex functionality (Tost et al, 2014) and associate with affective disorders involving frontal cortical function (Paterson et al, 2017).

In summary, we find that aberrant OFC synaptic plasticity and dysregulated attentional control processes in the presence of nicotine depend on nicotine interactions with NRG3/ErbB4 pathway. Nicotine dependence and withdrawal

symptoms include increased neurocognitive bias and elevated anxiety, that have been linked to OFC dysfunction (McClernon et al, 2015; O'Driscoll et al, 2014). Therefore, we propose that increased NRG3-ErbB4 signaling in the OFC in carriers of the NRG3 risk allele may result in dysregulated attentional control processes, perhaps leading to increased rates of nicotine dependence, particularly in individuals comorbid for psychiatric illnesses linked to genetic variation in NRG3. Thus, targeting the NRG3 pathway may represent a new direction for development of therapeutics for nicotine dependence.

\section{FUNDING AND DISCLOSURE}

This work was supported by the National Institutes of Health Grants R00-DA-032681 (JRT), DA031747 (PIO), DA041632 (TJG), and DA037421 (VP). All authors declare no financial and non-financial competing interests. We thank Dr Andres Buonanno at NIH for generously providing of ErbB4 antibody. The authors declare no conflict of interest.

\section{REFERENCES}

Alkondon M, Albuquerque EX (2001). Nicotinic acetylcholine receptor alpha7 and alpha4beta2 subtypes differentially control GABAergic input to CA1 neurons in rat hippocampus. $J$ Neurophysiol 86: 3043-3055.

Alkondon M, Braga MF, Pereira EF, Maelicke A, Albuquerque EX (2000). alpha7 nicotinic acetylcholine receptors and modulation of gabaergic synaptic transmission in the hippocampus. Eur $J$ Pharmacol 393: 59-67.

Alkondon M, Pereira EF, Barbosa CT, Albuquerque EX (1997). Neuronal nicotinic acetylcholine receptor activation modulates gamma-aminobutyric acid release from CA1 neurons of rat hippocampal slices. The J Pharmacol Exp Ther 283: 1396-1411.

Ashare RL, Falcone M, Lerman C (2014). Cognitive function during nicotine withdrawal: Implications for nicotine dependence treatment. Neuropharmacology 76: 581-591.

Baker TB, Breslau N, Covey L, Shiffman S (2012). DSM criteria for tobacco use disorder and tobacco withdrawal: a critique and proposed revisions for DSM-5. Addiction 107: 263-275.

Bean JC, Lin TW, Sathyamurthy A, Liu F, Yin DM, Xiong WC et al (2014). Genetic labeling reveals novel cellular targets of schizophrenia susceptibility gene: distribution of GABA and non-GABA ErbB4-positive cells in adult mouse brain. J Neurosci: Off J Soc Neurosci 34: 13549-13566.

Ben Hamida S, Darcq E, Wang J, Wu S, Phamluong K, Kharazia V et al (2013). Protein tyrosine phosphatase alpha in the dorsomedial striatum promotes excessive ethanol-drinking behaviors. J Neurosci: Off J Soc Neurosci 33: 14369-14378.

Bi LL, Sun XD, Zhang J, Lu YS, Chen YH, Wang J et al (2015). Amygdala NRG1-ErbB4 is critical for the modulation of anxietylike behaviors. Neuropsychopharmacology 40: 974-986.

Bianchi C, Ferraro L, Tanganelli S, Morari M, Spalluto G, Simonato $M$ et al (1995). 5-Hydroxytryptamine-mediated effects of nicotine on endogenous GABA efflux from guinea-pig cortical slices. $\mathrm{Br} \mathrm{J}$ Pharmacol 116: 2724-2728.

Bruijnzeel AW (2012). Tobacco addiction and the dysregulation of brain stress systems. Neurosci Biobehav Rev 36: 1418-1441.

Bruijnzeel AW, Alexander JC, Perez PD, Bauzo-Rodriguez R, Hall $\mathrm{G}$, Klausner $\mathrm{R}$ et al (2015). Acute nicotine administration increases BOLD fMRI signal in brain regions involved in reward signaling and compulsive drug intake in rats. Int J Neuropsychopharmacol 18. 
Claus ED, Blaine SK, Filbey FM, Mayer AR, Hutchison KE (2013). Association between nicotine dependence severity, BOLD response to smoking cues, and functional connectivity. Neuropsychopharmacology 38: 2363-2372.

Cloke JM, Winters BD (2015). alpha(4)beta(2) Nicotinic receptor stimulation of the GABAergic system within the orbitofrontal cortex ameliorates the severe crossmodal object recognition impairment in ketamine-treated rats: implications for cognitive dysfunction in schizophrenia. Neuropharmacology 90: 42-52.

Cole RD, Poole RL, Guzman DM, Gould TJ, Parikh V (2015). Contributions of beta2 subunit-containing nAChRs to chronic nicotine-induced alterations in cognitive flexibility in mice. Psychopharmacology 232: 1207-1217.

Couey JJ, Meredith RM, Spijker S, Poorthuis RB, Smit AB, Brussaard $\mathrm{AB}$ et al (2007). Distributed network actions by nicotine increase the threshold for spike-timing-dependent plasticity in prefrontal cortex. Neuron 54: 73-87.

D'Amore DE, Tracy BA, Parikh V (2013). Exogenous BDNF facilitates strategy set-shifting by modulating glutamate dynamics in the dorsal striatum. Neuropharmacology 75: 312-323.

Day M, Pan JB, Buckley MJ, Cronin E, Hollingsworth PR, Hirst WD et al (2007). Differential effects of ciproxifan and nicotine on impulsivity and attention measures in the 5-choice serial reaction time test. Biochem Pharmacol 73: 1123-1134.

Dickinson JA, Kew JN, Wonnacott S (2008). Presynaptic alpha 7and beta 2 -containing nicotinic acetylcholine receptors modulate excitatory amino acid release from rat prefrontal cortex nerve terminals via distinct cellular mechanisms. Mol Pharmacol 74: 348-359.

Eagle DM, Baunez C (2010). Is there an inhibitory-response-control system in the rat? Evidence from anatomical and pharmacological studies of behavioral inhibition. Neurosci Biobehav Rev 34: 50-72.

Gilbert DG, Robinson JH, Chamberlin CL, Spielberger CD (1989). Effects of smoking/nicotine on anxiety, heart rate, and lateralization of EEG during a stressful movie. Psychophysiology 26: 311-320.

Gold AL, Morey RA, McCarthy G (2015). Amygdala-prefrontal cortex functional connectivity during threat-induced anxiety and goal distraction. Biol Psychiatry 77: 394-403.

Gubner NR, Wilhelm CJ, Phillips TJ, Mitchell SH (2010). Strain differences in behavioral inhibition in a Go/No-go task demonstrated using 15 inbred mouse strains. Alcohol Clin Exp Res 34: 1353-1362.

Hahn B, Shoaib M, Stolerman IP (2003). Involvement of the prefrontal cortex but not the dorsal hippocampus in the attention-enhancing effects of nicotine in rats. Psychopharmacology 168: 271-279.

Harrison AA, Everitt BJ, Robbins TW (1999). Central serotonin depletion impairs both the acquisition and performance of a symmetrically reinforced go/no-go conditional visual discrimination. Behav Brain Res 100: 99-112.

Hartikainen KM, Knight RT (2003). Lateral and orbital prefrontal contributions to attention. In: Polich J (ed). Detection of Change: Event-related Potential and $f M R I$ Findings. Kluwer Academic Publishers: Boston/ Dordrecht/ New York/ London. pp 99-116.

Hartikainen KM, Ogawa KH, Knight RT (2012). Orbitofrontal cortex biases attention to emotional events. J Clin Exp Neuropsychol 34: 588-597.

Hartley CA, Phelps EA (2012). Anxiety and decision-making. Biol Psychiatry 72: 113-118.

Hatakeyama M, Kimura S, Naka T, Kawasaki T, Yumoto N, Ichikawa $\mathrm{M}$ et al (2003). A computational model on the modulation of mitogen-activated protein kinase (MAPK) and Akt pathways in heregulin-induced ErbB signalling. Biochem $J$ 373: 451-463.

Hu X, He W, Diaconu C, Tang X, Kidd GJ, Macklin WB et al (2008). Genetic deletion of BACE1 in mice affects remyelination of sciatic nerves. FASEB J 22: 2970-2980.
Huang YY, Kandel ER, Levine A (2008). Chronic nicotine exposure induces a long-lasting and pathway-specific facilitation of LTP in the amygdala. Learn Mem 15: 603-610.

Jamal A, Agaku IT, O'Connor E, King BA, Kenemer JB, Neff L (2014). Current cigarette smoking among adults-United States, 2005-2013. MMWR Morb Mortal Wkly Rep 63: 1108-1112.

Ji D, Dani JA (2000). Inhibition and disinhibition of pyramidal neurons by activation of nicotinic receptors on hippocampal interneurons. J Neurophysiol 83: 2682-2690.

Ji D, Lape R, Dani JA (2001). Timing and location of nicotinic activity enhances or depresses hippocampal synaptic plasticity. Neuron 31: 131-141.

Kao WT, Wang Y, Kleinman JE, Lipska BK, Hyde TM, Weinberger DR et al (2010). Common genetic variation in Neuregulin 3 (NRG3) influences risk for schizophrenia and impacts NRG3 expression in human brain. Proc Natl Acad Sci USA 107: 15619-15624.

Kirshenbaum AP, Jackson ER, Brown SJ, Fuchs JR, Miltner BC, Doughty AH (2011). Nicotine-induced impulsive action: sensitization and attenuation by mecamylamine. Behav Pharmacol 22: 207-221.

Kofalvi A, Sperlagh B, Zelles T, Vizi ES (2000). Long-lasting facilitation of 4-amino-n-[2,3-(3)H]butyric acid ([(3)H]GABA) release from rat hippocampal slices by nicotinic receptor activation. J Pharmacol Exp Ther 295: 453-462.

Kolokotroni KZ, Rodgers RJ, Harrison AA (2011). Acute nicotine increases both impulsive choice and behavioural disinhibition in rats. Psychopharmacology 217: 455-473.

Kringelbach ML (2005). The human orbitofrontal cortex: linking reward to hedonic experience. Nat Rev Neurosci 6: 691-702.

Krivosheya D, Tapia L, Levinson JN, Huang K, Kang Y, Hines R et al (2008). ErbB4-neuregulin signaling modulates synapse development and dendritic arborization through distinct mechanisms. J Biol Chem 283: 32944-32956.

Kuhn S, Schubert F, Gallinat J (2010). Reduced thickness of medial orbitofrontal cortex in smokers. Biol Psychiatry 68: 1061-1065.

Lagostena L, Trocme-Thibierge C, Morain P, Cherubini E (2008). The partial alpha7 nicotine acetylcholine receptor agonist S 24795 enhances long-term potentiation at CA3-CA1 synapses in the adult mouse hippocampus. Neuropharmacology 54: 676-685.

Li Y, Yuan K, Cai C, Feng D, Yin J, Bi Y et al (2015). Reduced frontal cortical thickness and increased caudate volume within fronto-striatal circuits in young adult smokers. Drug Alcohol Depend 151: 211-219.

Loos M, Mueller T, Gouwenberg Y, Wijnands R, van der Loo RJ, BMPC Neuro et al (2014). Neuregulin-3 in the mouse medial prefrontal cortex regulates impulsive action. Biol Psychiatry 76: 648-655.

Loukola A, Wedenoja J, Keskitalo-Vuokko K, Broms U, Korhonen $\mathrm{T}$, Ripatti $\mathrm{S}$ et al (2014). Genome-wide association study on detailed profiles of smoking behavior and nicotine dependence in a twin sample. Mol Psychiatry 19: 615-624.

Ma H, Lesne S, Kotilinek L, Steidl-Nichols JV, Sherman M, Younkin L et al (2007). Involvement of beta-site APP cleaving enzyme 1 (BACE1) in amyloid precursor protein-mediated enhancement of memory and activity-dependent synaptic plasticity. Proc Natl Acad Sci USA 104: 8167-8172.

Maki-Marttunen V, Kuusinen V, Perakyla J, Ogawa KH, Brause M, Brander A et al (2017). Greater attention to task-relevant threat due to orbitofrontal lesion. J Neurotrauma 34: 400-413.

Mansvelder HD, McGehee DS (2000). Long-term potentiation of excitatory inputs to brain reward areas by nicotine. Neuron 27: 349-357.

McClernon FJ, Addicott MA, Sweitzer MM (2015). Smoking abstinence and neurocognition: implications for cessation and relapse. Curr Top Behav Neurosci 23: 193-227.

McDonald MP, Wong R, Goldstein G, Weintraub B, Cheng SY, Crawley JN (1998). Hyperactivity and learning deficits in 
transgenic mice bearing a human mutant thyroid hormone betal receptor gene. Learn Mem 5: 289-301.

McGaughy J, Sarter M (1995). Behavioral vigilance in rats: task validation and effects of age, amphetamine, and benzodiazepine receptor ligands. Psychopharmacology 117: 340-357.

Mendez IA, Damborsky JC, Winzer-Serhan UH, Bizon JL, Setlow B (2013). Alpha4beta2 and alpha7 nicotinic acetylcholine receptor binding predicts choice preference in two cost benefit decisionmaking tasks. Neuroscience 230: 121-131.

Nakauchi S, Sumikawa K (2012). Endogenously released ACh and exogenous nicotine differentially facilitate long-term potentiation induction in the hippocampal CA1 region of mice. Eur J Neurosci 35: 1381-1395.

Nides M (2008). Update on pharmacologic options for smoking cessation treatment. Am J Med 121: S20-S31.

O'Driscoll C, Laing J, Mason O (2014). Cognitive emotion regulation strategies, alexithymia and dissociation in schizophrenia, a review and meta-analysis. Clin Psychol Rev 34: 482-495.

Olive MF, Mehmert KK, Koenig HN, Camarini R, Kim JA, Nannini MA et al (2003). A role for corticotropin releasing factor (CRF) in ethanol consumption, sensitivity, and reward as revealed by CRFdeficient mice. Psychopharmacology 165: 181-187.

Ortega LA, Tracy BA, Gould TJ, Parikh V (2013). Effects of chronic low- and high-dose nicotine on cognitive flexibility in C57BL/ 6J mice. Behav Brain Res 238: 134-145.

Ortinski PI, Turner JR, Barberis A, Motamedi G, Yasuda RP, Wolfe $\mathrm{BB}$ et al (2006). Deletion of the GABA(A) receptor alphal subunit increases tonic $\mathrm{GABA}(\mathrm{A})$ receptor current: a role for $\mathrm{GABA}$ uptake transporters. J Neurosci 26: 9323-9331.

Papaleo F, Yang F, Paterson C, Palumbo S, Carr GV, Wang Y et al (2016). Behavioral, neurophysiological, and synaptic impairment in a transgenic neuregulin1 (NRG1-IV) murine schizophrenia model. J Neurosci 36: 4859-4875.

Poorthuis RB, Bloem B, Schak B, Wester J, de Kock CP, Mansvelder HD (2013). Layer-specific modulation of the prefrontal cortex by nicotinic acetylcholine receptors. Cereb Cortex 23: 148-161.

Paterson C, Wang Y, Hyde TM, Weinberger DR, Kleinman JE, Law AJ (2017). Temporal, diagnostic, and tissue-specific regulation of NRG3 isoform expression in human brain development and affective disorders. Am J Psychiatry 174: 256-265.

Rauch SL, Wedig MM, Wright CI, Martis B, McMullin KG, Shin LM et al (2007). Functional magnetic resonance imaging study of regional brain activation during implicit sequence learning in obsessive-compulsive disorder. Biol Psychiatry 61: 330-336.

Rose RJ, Broms U, Korhonen T, Dick DM, Kaprio J (2009). Genetics of smoking behavior. Handbook of Behavior Genetics 411-432.

Rousseau SJ, Jones IW, Pullar IA, Wonnacott S (2005). Presynaptic alpha7 and non-alpha7 nicotinic acetylcholine receptors modulate $[3 \mathrm{H}] \mathrm{d}$-aspartate release from rat frontal cortex in vitro. Neuropharmacology 49: 59-72.
Schoenbaum G, Chang CY, Lucantonio F, Takahashi YK (2016). Thinking outside the box: orbitofrontal cortex, imagination, and how we can treat addiction. Neuropsychopharmacology 41: 2966-2976.

Stolerman IP, Mirza NR, Hahn B, Shoaib M (2000). Nicotine in an animal model of attention. Eur J Pharmacol 393: 147-154.

Tang J, Dani JA (2009). Dopamine enables in vivo synaptic plasticity associated with the addictive drug nicotine. Neuron 63: 673-682.

Torregrossa MM, Quinn JJ, Taylor JR (2008). Impulsivity, compulsivity, and habit: the role of orbitofrontal cortex revisited. Biol Psychiatry 63: 253-255.

Torres OV, O'Dell LE (2016). Stress is a principal factor that promotes tobacco use in females. Prog Neuropsychopharmacol Biol Psychiatry 65: 260-268.

Tremblay L, Schultz W (2000). Reward-related neuronal activity during go-nogo task performance in primate orbitofrontal cortex. J Neurophysiol 83: 1864-1876.

Turner JR, Ray R, Lee B, Everett L, Xiang J, Jepson C et al (2014). Evidence from mouse and man for a role of neuregulin 3 in nicotine dependence. Mol Psychiatry 19: 801-810.

Turner TJ (2004). Nicotine enhancement of dopamine release by a calcium-dependent increase in the size of the readily releasable pool of synaptic vesicles. J Neurosci 24: 11328-11336.

Ursu S, Carter CS (2009). An initial investigation of the orbitofrontal cortex hyperactivity in obsessive-compulsive disorder: exaggerated representations of anticipated aversive events? Neuropsychologia 47: 2145-2148.

Vazquez-Sanroman DB, Monje RD, Bardo MT (2016). Nicotine self-administration remodels perineuronal nets in ventral tegmental area and orbitofrontal cortex in adult male rats. Addict Biol 22: 1743-1755.

Volkow ND, Fowler JS (2000). Addiction, a disease of compulsion and drive: involvement of the orbitofrontal cortex. Cereb Cortex 10: $318-325$.

Vullhorst D, Mitchell RM, Keating C, Roychowdhury S, Karavanova I, Tao-Cheng JH et al (2015). A negative feedback loop controls NMDA receptor function in cortical interneurons via neuregulin 2/ErbB4 signalling. Nat Commun 6: 7222.

Wang BW, Liao WN, Chang CT, Wang SJ (2006). Facilitation of glutamate release by nicotine involves the activation of a $\mathrm{Ca} 2$ $+/$ calmodulin signaling pathway in rat prefrontal cortex nerve terminals. Synapse 59: 491-501.

Welsby PJ, Rowan MJ, Anwyl R (2009). Intracellular mechanisms underlying the nicotinic enhancement of LTP in the rat dentate gyrus. Eur J Neurosci 29: 65-75.

Yechiam E, Goodnight J, Bates JE, Busemeyer JR, Dodge KA, Pettit GS et al (2006). A formal cognitive model of the go/no-go discrimination task: evaluation and implications. Psychol Assess 18: $239-249$. 